\title{
Endoscopy Induced Gastric Pneumatosis
}

\section{Pneumatose Gástrica Induzida por Endoscopia}

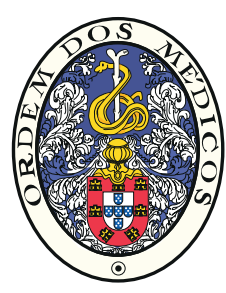

Carlos BILREIRO $\rrbracket^{1}$, Jorge BRITO1

Acta Med Port 2017 Mar;30(3):252-252 - https://doi.org/10.20344/amp.7403

Keywords: Aged; Endoscopy; Pneumatosis Cystoides Intestinalis; Stomach Diseases

Palavras-chave: Doenças do Estômago; Endoscopia; Idoso; Pneumatose Cistoide Intestinal
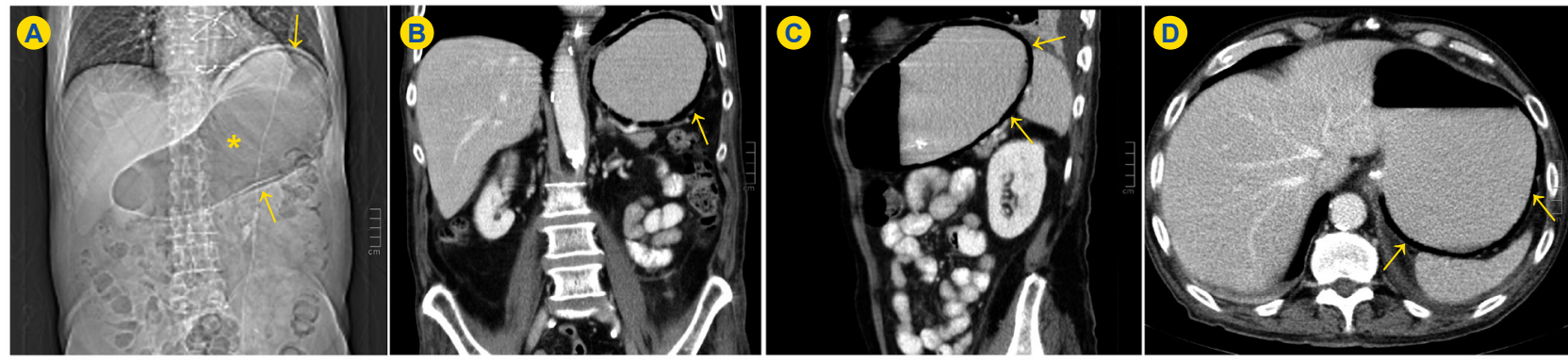

Figure 1 - (A) Scout view showing marked stomach distension and hipodensity $\left(^{*}\right)$, with additional linear hipodensity in the fundus wall (arrows). Contrast-enhanced CT scan, axial (D), and sagittal (C) and coronal (B) reformatted images revealing gastric pneumatosis (arrows)

A 78-year-old man, being studied for wasting syndrome with unspecific symptoms, performed a contrast-enhanced computed tomography (CT) scan, revealing stomach hipodensity and distension with linear hipodensity in the fundus wall, promptly visible on the scout view (Fig. 1A). On the axial and multiplanar reconstruction images there are findings of gastric pneumatosis (intramural gas) (Fig.s 1B, $1 \mathrm{C}, 1 \mathrm{D})$, a rare finding, the stomach being the least common location of intramural pneumatosis in the gastrointestinal tract. Several causes have been described, emphysematous gastritis being the most lethal. ${ }^{1-4}$

There were no relevant clinical or analytical findings, no signs of pneumatosis in other segments of the gastrointestinal tract or the portal vein. The patient underwent an upper gastrointestinal endoscopy two days before, where two biopsies were performed in the duodenal bulb. This prompted the diagnosis of endoscopy-induced gastric pneumatosis. Therapy was supportive and the control CT performed eight

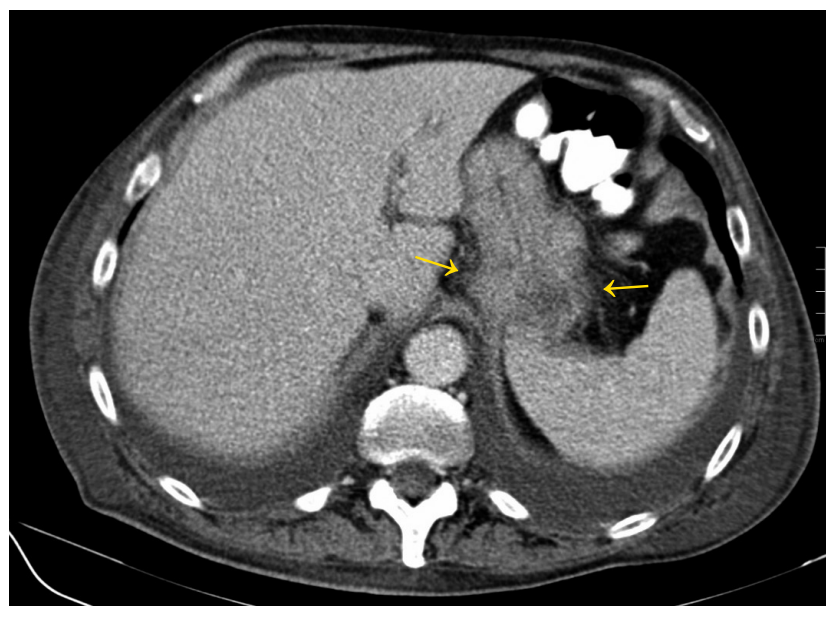

Figure 2 - Contrast-enhanced CT scan performed eight days after the diagnosis was made, showing spontaneous resolution of gastric pneumatosis (arrows) days later revealed spontaneous resolution (Fig. 2).

\section{REFERENCES}

1. Johnson PT, Horton KM, Edil BH, Fishman EK, Scott WW. Gastric pneumatosis: the role of CT in diagnosis and patient management. Emerg Radiol. 2011;18:65-73.

2. Ferreira AO, Loureiro AL, Sousa HT, Brito J. Gastric pneumatosis: a radiological diagnosis with a wide clinical spectrum. Endoscopy. 2012;44:E437-8.

3. Huang CT, Liao WY. Emphysematous gastritis: a deadly infectious disease. Scand J Infect Dis. 2009;41:317-9.

4. Ba-Ssalamah A, Prokop M, Uffmann M, Pokieser P, Teleky B, Lechner G. Dedicated multidetector CT of the stomach: spectrum of diseases. Radiographics. 2003;23:625-44.

\footnotetext{
1. Serviço de Radiologia. Centro Hospitalar do Algarve. Portimão. Portugal.

$\square$ Autor correspondente: Carlos Bilreiro. carlosbilreiro@hotmail.com

Recebido: 16 de janeiro de 2016 - Aceite: 02 de agosto de 2016 | Copyright @ Ordem dos Médicos 2017
} 